\title{
Duodenal strongyloidiasis infection mimicking lymphangiectasia
}

\author{
Muhammad Bilal', Nisar Ahmed ${ }^{2}$ \\ ${ }^{1}$ Medical Officer, Intensive Care Unit, Zia-ud-din University Hospital, Karachi, Pakistan, ${ }^{2}$ Consultant Gastroenterologist, \\ Department of Gastroenterology and Hepatology, Park Plaza Hospital, Houston, U.S.A
}

Strongyloides stercoralis infection usually causes a chronic asymptomatic intestinal infection or otherwise non-specific generalized complaints. The diagnosis of strongyloidiasis by routine stool examination is very limited. Endoscopic findings in strongyloidiasis range from mucosal granularity to friable edema to frank ulceration or Small bowel obstruction secondary to intense infestation. The pathological examination of tissue biopsy and aspirate can give the definitive diagnosis. We report a case of middle age patient who presented with the symptoms of weight loss and diarrhea. On evaluation, upper GI endoscopy (EGD) showed the findings of lymphangiectasia but biopsy findings were consistent with strongyloidiasis

Access this article online Website:

http://nepjol.info/index.php/AJMS DOI: $10.3126 /$ ajms.v8i5.17476

E-ISSN: 2091-0576

P-ISSN: 2467-9100 which was successfully treated with Ivermectin $200 \mu \mathrm{g} / \mathrm{kg}$, given for two days.

Key words: Intestinal strongyloidiasis, Esophagogastroduodenoscopy (EGD), ELISA

\section{INTRODUCTION}

Strongyloides stercoralis, belonging to phylum Nematode and commonly known as thread worm, has the ability to infest the host tissue and can cause wide spectrum of diseases depending upon the host immunity and its life cycle. Chronic infection can also persist without causing any symptoms. Routine stool examination for detecting ova and parasite has low sensitivity. ${ }^{1-3}$ The histopathological examination of suspicious biopsy samples is very important to diagnose or exclude strongyloides and other intestinal infections.

\section{CASE REPORT}

A 47 year old male from Colombia presented with the history of weight loss and diarrhea of 4 weeks duration. Symptoms started gradually and worsened with time. No associated complain of vomiting, abdominal pain, bleeding per rectum, night sweats, low appetite or fever were reported by the patient. No history of recent travel, eating out or sick contact. Review of other examinations was negative.
On investigating, the following findings were revealed;

- Complete blood count

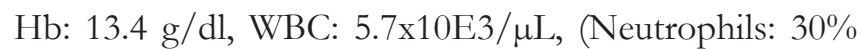
Lypmhocyte: 5\% Eosinophills: 0.01\%)

Plt: $241000 / \mu \mathrm{L}$.

- $\quad$ Stool test

Stool detailed report was absent for ova \& parasites, leukocytes and blood. Repeated stool tests for ova and parasites were negative.

- Immunoassay

ELISA(Enzyme linked immunosorbant assay) was negative for serum larval antigen.

- Esophagogastroduodenoscopy

It showed findings suggestive of lymphangiectasia (Figure 1). Histopathology of biopsied specimen revealed presence of Strongyloides stercoralis in the mucosa (Figure 2). 


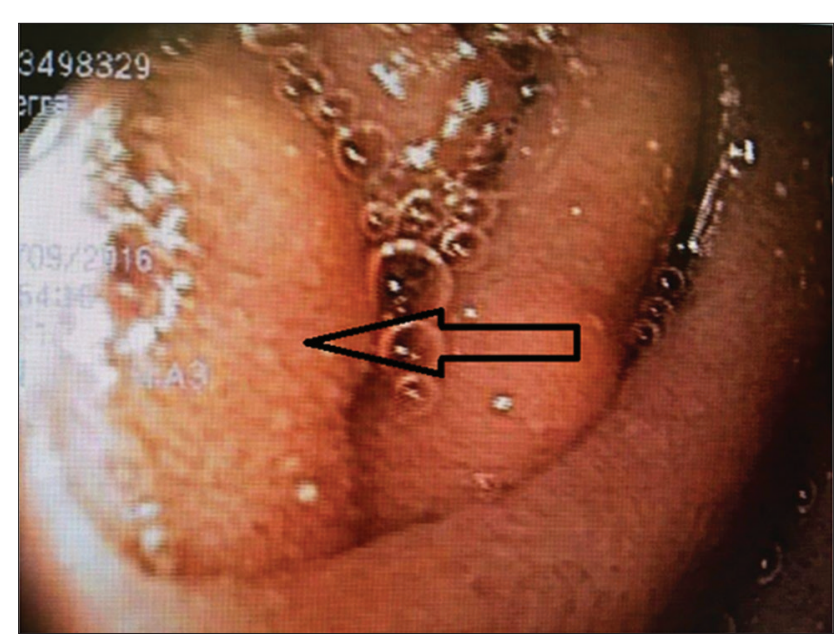

Figure 1: Showing lesion mimicking lymphangiectasia

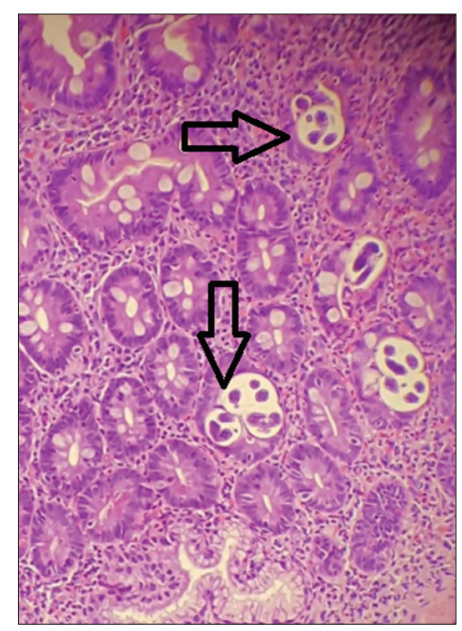

Figure 2: Showing ova of Strongyloide stercoralis inside the mucosa of Small intestine

Per Biopsy findings, Ivermectin $200 \mu \mathrm{g} / \mathrm{kg}$ was given for two days. Diarrheal episodes were resolved after one week of follow-up. Patient expressed improvement in his weight upon further follow-up with complete resolution of the symptoms.

\section{DISCUSSION}

Strongyloides stercoralis is a common parasite of the gastrointestinal tract. The global prevalence is estimated between 30-100 million, and this is especially common in the tropical and subtropical areas. ${ }^{1}$ Human infection occurs when filariform larvae penetrate the intact skin. The larvae are transported to the lungs through the blood stream and then through the alveoli and bronchi they reach the pharynx where they are swallowed into the stomach and the small intestine. ${ }^{4}$ To make the diagnosis of strongyloide stercoralis, many diagnostic tests are available with distinct sensitivity and specificity. Routine stool examination has limited efficacy in detecting larvae of the infective organism ( $<50$ percent sensitivity), reason being the fact that larvae shed in the stool intermittently and patients differ with regard to the burden of infectious organism. ${ }^{5}$ Other special stool test that can be productive of positive results include the Harada-Mori filter paper technique, the Baerman concentration technique, and a modified agar plate method but there frequent use is limited due to the fact that even three or more stool samples can fail to detect the organism. ${ }^{6,7}$ Immunoassay techniques like ELISA has proven out to be useful to detect the organism in immunocompetent individuals, both in asymptomatic and symptomatic strongyloidiasis. ${ }^{8,9}$ Whereas, ELISA can be falsely negative in immunocompromised host. ${ }^{10}$ Furthermore, patient can be tested falsely positive if other helminth infection is present as a result of cross reaction between helminth infection. ${ }^{11}$ Newly invented technique, Luciferase immunoprecipitation system (LIPS), is alternative to ELISA based method but it is not commercially available. ${ }^{12}$ Upper GI endoscopy is not typically expected to build up a diagnosis of strongyloidiasis. Nonetheless, it might be performed in patients with gastrointestinal side effects with unsuspected disease. Intestinal strongyloidiasis has a broad range of endoscopic features. ${ }^{13}$

- In the duodenum, lesions may appear as edema, brown discoloration of mucosa, subepithelial hemorrhages and megaduodenum.

- In the colon, variety of endoscopic presentations includes aphthous ulcers, xanthoma-like lesions, serpiginous ulcerations, and erosions.

- Stomach lesions may appear like thickening of mucosal folds or mucosal erosions. ${ }^{14}$

The pathological examination of tissue biopsy and aspirate can give the definitive diagnosis. ${ }^{4}$

\section{CONCLUSION}

Strongyloides stercoralis is a common parasite of the gastrointestinal tract and usually causes a chronic asymptomatic intestinal infection. And those who do develop symptoms tend to have non-specific, or generalized complaint. Though, immunocompromised patients can develop hyperinfection with high mortality rates. Hence high index of suspicion is required for diagnosis. Biopsy is the gold standard for diagnosis. Ivermectin is the drug of choice.

\section{REFERENCES}

1. Davila PM, Fortun J, Velez RL, Norman F, Montes de Oca M, Zamarron $\mathrm{P}$, et al. Transmission of tropical and geographically restricted infections during solid-organ transplantation. Clinical Microbiology Review 2008; 21(1):60-96. 
2. Patel PK and Khandekar R. Intestinal parasitic infections among school children of Dhahira Region of Oman. Saudi Med J 2006;27(5):627-632.

3. Scrimgeour EM, Mehta FR and Suleiman AMJ. Infectious and tropical diseases in Oman: a review. The American Journal of Tropical Medicine and Hygiene 1999;61(6):920-925.

4. Agrawal V, Agarwal T and Ghoshal UC. Intestinal strongyloidiasis: a diagnosis frequently missed in the tropics. Transactions of the Royal Society of Tropical Medicine and Hygiene 2009; 103(3):242-246.

5. Boulware DR, Stauffer WM $3^{\text {rd }}$ and Walker PF. Hypereosinophilic syndrome and mepolizumab. New England Journal of Med 2008; 358; 2838-2840.

6. Rosenblatt JE. Clinical importance of adequately performed stool ova and parasite examinations. Clinical Infectious Diseases 2006; 43(6): 794-795.

7. Hirata T, Nakamura H, Kinjo N, Hokama A, Kinjo F, Yamane N, et al. Increased detection rate of Strongyloides stercoralis by repeated stool examinations using the agar plate culture method. The American Journal of Tropical Medicine and Hygiene 2007; 77(4):683-684.

8. Carroll SM, Karthigasu KT and Grove DI. Serodiagnosis of human strongyloidiasis by an enzyme-linked immunosorbent assay. Transactions of the Royal Society of Tropical Medicine and Hygiene 1981; 75:706.

9. Neva FA, Gam AA and Burke J. Comparison of larval antigens in an enzyme-linked immunosorbent assay for strongyloidiasis in humans. Journal of Infectious Diseases 1981; 144(5):427-432.

10. Abdalla J, Saad M, Myers JW and Moorman JP. An elderly man with immunosuppression, shortness of breath, and eosinophilia. Clinical Infectious Diseases 2005; 40(10):1535-1536.

11. Greiner K, Bettencourt $\mathrm{J}$ and Semolic C. Strongyloidiasis: a review and update by case example. Clinical Laboratory Sciences 2008; 21(2):82-88.

12. Ramanathan $R$, Burbelo PD, Groot $S$, Ladarola M, Neva F and Nutman T. A luciferase immunoprecipitation systems assay enhances the sensitivity and specificity of diagnosis of Strongyloides stercoralis infection. Journal of Infectious Diseases 2008; 198(3):444-451.

13. Sreenivas DV, Kumar A, Kumar YR, Bharavi C, Sundaram C and Gayathri K. Intestinal strongyloidiasis-a rare opportunistic infection. Indian J Gastroenterol: J Indian Soc Gastroenterol 1997; 16(3):105-106.

14. Thompson BF, Fry LC, Wells CD, Olmos M, Lee DH, Lazenby AJ, et al. The spectrum of Gl strongyloidiasis: an endoscopicpathologic study. Gastrointestinal Endoscopy 2004; 59(7):906-910.

Authors contribution:

MB- Design of the case report, reviewed the literature, manuscript preparation and critical revision of the manuscript; NA- Concept of the case report, images of the endoscopic and histopathological findings.

Orcid ID:

Dr. Muhammad Bilal: (i) http://orcid.org/0000-0002-1088-2313

Source of Support: None, Conflict of Interest: None. 